\title{
A Research on the Design Strategy of Urban Waterfront Landscape --- A Case Study of the Surrounding Cities of South Dongting Lake
}

\author{
Hongquan Sun \\ The Department of Art and Design, Hunan City University, Yiyang Hunan, 413000,China
}

Keywords: Urbanization, Waterfront landscape, Design strategy, South Dongting Lake.

\begin{abstract}
With the acceleration of urbanization process, scenic spots around the country have got a more ideal space for development. Especially in the areas connected with scenic spots, the development of urbanization is more urgent. Therefore, how to realize the scientific planning of urbanization in scenic spots and urban areas needs to be further explored. The urban waterfront landscape design includes not only the planning and coordination of scenic spots and urban areas, but also the harmonious construction of waters along the river and natural landscape. Based on this, to further enhance the design effects of urban waterfront landscape, this paper makes an analysis combined with a case study of the construction of surrounding cities of South Dongting Lake for reference.
\end{abstract}

\section{Introduction}

The planning and construction of urbanization in the areas connected with waterfront scenic spots have regional characteristics in terms of social and economic development, spatial planning, landscape design and overall management, but in the actual development process, the trend of urbanization has been enhanced due to the rapid development of tourism economy, and coupled with people's misunderstanding of the urban waterfront landscape construction, the urban areas have lost good self-protection and development barrier in the development process, triggering the conflicts of coordination in terms of urban development and scenic spot management. For surrounding cities of South Dongting Lake, not only Yiyang as the central city for the economic development of Dongting Lake District has an advantageous geographical location known as "800 li Dongting Lake", but also the development of these cities gradually rises in the aspects of green energy production, industrial development and transportation, which is conducive to promoting the planning and construction of urban waterfront landscape design.

\section{An Analysis of the South Dongting Lake Waterfront Landscape Design}

\section{Waterfront characteristics}

Waterfront is a connected area integrating urban areas and water bodies, a lubricant to promote the coordinated development of macro and micro urban environment, and a central zone of the city. Therefore, it has also become one of the main manifestations of urban landscape. In the construction and design process, waterfront is also influenced by natural environment and human factors, and thus it has double attributes, namely, natural and cultural attributes; the attributes of waterfront landscape represent not only the characteristics of urban waterfront, but also the impact of waterfront environment on the city. The waterfront landscape design mainly follows this design concept of "natural and cultural harmony" to constantly optimize the constitution of waterfront natural landscape, and implant the landscape culture in the urban human settlement environment, thus transforming from the design of macro environment gradually into the construction of micro environment, that is, follow the laws of nature for waterfront environment to carry out social production practices; only by taking the ecological protection of social and economic development benefits as the development core, can waterfront scenic spots be really integrated into the modern 
urban construction in order to further enhance the design connotation of harmony between man and nature.

\section{An analysis of landscape resources in South Dongting Lake}

Among the surrounding cities of South Dongting Lake, Yiyang has achieved significant economic development by virtue of landscape resources in Dongting Lake, and thus Dongting Lake known as the mother of Yiyang is the backbone force of regional economic development in Yiyang and plays a powerful role in promoting the industry, agriculture and the tertiary industry in urban areas ${ }^{[1]}$. Therefore, to strengthen the protection of landscape resources in South Dongting Lake is an important safeguard to ensure the sustainable economic development of surrounding cities. The advantages of landscape resources in South Dongting Lake are manifested as follows: (1) Dongting Lake as one of the freshwater lakes in China enjoy a vast area and fertile soil, and the abundant heat and product production in this area has become a major driving force for the economic development in China. But with the destruction of human economic activities, Dongting Lake has been divided into three parts currently, and South Dongting Lake is a part of it. (2) South Dongting Lake, located in the southwest of Dongting Lake and the north-central part of Yiyang, connects multiple villages and towns such as Shatou Town in Ziyang District, Lanxi Town and Sanyangtang Town in Henshan District, etc. including the agriculture and forestry field in Datonghu District, covering a water area of 917 square kilometers. (3) South Dongting Lake is a part of the Yangtze River system, and the water of Xiangjiang River and three river estuaries of the Yangtze River all flow into South Dongting Lake, but in recent years, South Dongting Lake has been divided into multiple lakes by various major lake water systems due to serious sediment accumulation, including Wanzi Lake and Dongnan Lake both with a large water surface area; meanwhile, these lakes can exert the natural functions of flood control and climate regulation, and form powerful protection of migratory birds in winter and summer since there are a variety of ancient aquatic and wild animals as well as a good wetland environment.

\section{An Analysis of the Current Situation of the South Dongting Lake Waterfront Landscape Environment}

With the acceleration of urbanization process, water bodies have been gradually enhanced from simple use in the initial stage to development and utilization at present, the population has been on the increase, economic entities have gradually approached to the areas along the river, and economy and trade have become prosperous, which has greatly enhanced the advantages of the waterfront, but brought many negative impacts accordingly including water body pollution, overfishing, and eco-development imbalance. With the intensification of development efforts, the degree of pollution has increased instead of decreasing, and the environment carrying capacity of urban waterfront has gradually decreased, and even the ecosystem has begun to be destroyed; coupled with the artificial excessive use, the ecological structure has lost its stability, thus affecting the ecological balance system of the entire urban waterfront, and reducing the urban water space utilization. In addition, the waterfront in some areas has been used improperly such as long-term excessive use of the waterfront or the construction of deserted areas, leading to the damaged landscape environment. The land transportation has gradually replaced the traditional waterway transportation, so changes have taken place in the water and land space structure in some areas, and coupled with the factors such as the relocation of the population, the devastation of sites, and the aging of building facilities, the waterfront landscape has lost its original advantages and values.

\section{Design Strategy of Urban Waterfront Landscape}

Urban construction is also a great work of art. Particularly, the urban waterfront landscape design builds the waterfront into an urban area with a beautiful environment and convenient transportation which is suitable for human relaxation and entertainment as well as economic development in order to drive the regional economic development and increase people's living standards, which is the goal 
of landscape design. Therefore, in order to achieve this goal, the waterfront landscape design of South Dongting Lake should take the concept of sustainable development as the core, as well as the construction and shaping of a landscape city as the guideline to perfect the design theory system of urban waterfront; in the actual operation process, the landscape characteristics of the surrounding cities of South Dongting Lake and the practical situation of economic development in these cities are taken as a basis to present a characteristic waterfront landscape with modern development characteristics and meet the sustainable development requirements through the construction method of landscape design ${ }^{[3]}$. Due to the environment and ecosystem pollution, the life of coast residents have been severely affected, and the beautiful characteristic waterfront landscape has become more desolate $^{[2]}$. For example, some waterfront shorelines of South Dongting Lake were subject to the artificial constructive destruction, the construction quantity of industrial plants was increased, and the wastewater and sewage discharge was excessive. As a result, the river was seriously polluted, and the water quality was destroyed, which affected the normal daily life of residents, endangered the life safety of rare animals in the lake, and brought a negative impact on the regional waterfront landscape.

\section{Achieve the optimal configuration of waterfront functions through characteristic landscape}

Some waterfronts have gradually faded out of the center of city life and been forgotten by people along with the changes of urban structure, resulting in the situation where waterfront development was in recession and even the waterfronts fell into disuse. Therefore, in the initial stage of landscape design, it is necessary to take the resurrection of waterfront functions as the key content of the design in order to fully enhance the development and application of the water valve function of the waterfront, especially the commercial application function and the application function of tourist facilities, and to make a rational use of the advantages of urban waterfront; meanwhile, in the design process, it is also necessary to focus on increasing the exhibition of regional historical and cultural characteristics such as Lingyun Tower and Zhenjiang Tower in order to enhance the life appeal of waterfront landscape ${ }^{[4]}$. If the waterfront in this urban area is polluted and destroyed to a certain extent, it is necessary to make a comprehensive investigation and analysis of the pollution situation of the waterfront according to the development strength and exploitation intensity of this urban area in order to work out a reasonable solution. In terms of the landscape design content, it is necessary to set environmental protection as one of the key points of development in order to effectively improve various ecological functions of the waterfront, promote the overall exploitation and coordinated development of the comprehensive functions of regional cities, and avoid the loss of some urban functions such as business office function and industrial development center. Next, improve the greening management of residential areas in the waterfront, carry out the reasonable planning of the residential living area, appropriately expand or maintain the original green areas, and promote harmonious relations between local residents and the waterfront, thus achieving a happy ending of harmony between man and nature.

Whether it is to implement the development and design of urban waterfront according to local conditions, or to improve the maintenance management of the waterfront combined with the local construction and development needs, the design forms with the above function configuration both take the maintenance and construction of urban development view as the core to carry out the work. Only by regarding the water vein linear unity as the development focus of urban waterfront, can the structural system of urban water vein landscape be improved in order to ensure the function integrity of urban waterfront and establish an ecological and efficient urban waterfront landscape design system.

\section{Highlight the city beauty of the waterfront through the natural landscape advantages}

The waterfront landscape and environment design mainly includes natural landscape, cultural landscape and perfect artificial facilities, which is specifically manifested as follows: topographic and geomorphic characteristics, water characteristics, plants and animals, historical and cultural landscape, and social and economic development in urban areas. From an analysis of natural environment factors and cultural landscape characteristics, it is found that only by demonstrating the 
characteristics of urban waterfront, can the waterfront area get healthy construction; meanwhile, the sound construction of cultural landscape and natural landscape can provide the future landscape design with a reliable basis for creation and add a unique style to the urban waterfront landscape design $^{[6]}$. The characteristics of the urban environment form a direct impact on the effects of the waterfront landscape design, and therefore, in order to further enhance the waterfront characteristics, it is necessary to gain a comprehensive understanding of the waterfront background and characteristics and make targeted and reasonable transformation and sublimation in the process of the waterfront landscape design so as to ensure that the landscape design completed has unique "beauty of implication" and "humanistic beauty", demonstrate the culture connotations and ethnic characteristics of this area in the waterfront landscape design in order to obtain more valuable improvements in the future development; the waterfront landscape can also become a beautiful historical scenery after years of baptism. The street, infrastructure and shoreline design of the waterfront are important contents of artificial facilities as well as indispensable bright colors for the construction of urban waterfront; meanwhile, these contents also add a touch of traditional Chinese realistic painting to the construction of the natural landscape in the urban waterfront, further enhancing the cultural deposits of natural waterscape ${ }^{[7-8]}$. The hydrophilic attitude is required in the waterfront landscape design, and therefore, it is necessary to strengthen the ties between urban landscape and water culture, and establish a cultural building with a symbolic significance as the landmark for the urban water culture construction in order to fully demonstrate the profound connotation of the water culture in the waterfront; carry out appropriate water sightseeing activities so that people have the opportunity to get close to the beautiful buildings in the waterfront, thus designing a waterscape full of cultural characteristics.

\section{Perfect the space structure design of the waterfront combined with urban characteristics}

Optimizing the landscape space structure is a key content to complete the urban waterfront landscape design as well as a decisive factor in relation to the waterfront landscape design quality. Therefore, how to strengthen the effective combination of water construction and land construction in the waterfront is of very important practical significance to the waterfront landscape design. Before the landscape design work, it is necessary to analyze the morphological characteristics of regional space and understand the necessary relations between various elements in order to strengthen the optimal combination of landscape elements and space structure in the actual construction work for the design of a perfect waterfront landscape space form ${ }^{[9-10]}$. For example, in terms of the space form characteristic expression of the surrounding cities of South Dongting Lake, some cities belong to the linear extension construction, and thus exhibit an obvious edge characteristic in space form. The landscape design should seize this characteristic, and give priority to the control of urban skyline so that people can fully feel the unique style and feature of urban waterfront; the arrangement of landscape position should fit in the urban atmosphere and make an effective combination of the cultural characteristics of the city and the waterfront in order to fully demonstrate the advantages of water culture; meanwhile, the arrangement of scenic spots in the waterfront and the distribution of scenic spots also should rely on the extended water bodies as the support of construction to further enhance the exhibiting effects of urban waterfront waterscape characteristics.

\section{Conclusion}

In summary, to further enhance the effectiveness and uniqueness of urban construction in the process of urban waterfront landscape design, it is necessary to first analyze the characteristics of the regional landscape environment, and then combined with the current development situation, put forward more reasonable design strategies as follows: firstly, optimize the allocation of waterfront urban functions; secondly, combine with the natural landscape advantages to highlight the beauty of historical characteristics in urban areas; finally, master the characteristics of urban development, and constantly optimize the spatial structure design of the waterfront. 


\section{Acknowledgement}

Fund Project: On the Design Strategy of Urban Waterfront Landscape for the Surrounding Cities of South Dongting Lake Topic Number: 2014YS30

\section{References}

[1] Chen Ye \& Zhang Bin. Urban Design Based on Water Environment--A Case Study of Meilonghu District, Chunhua Town, Nanjing, Chinese Gardens, 2014 (04): 16-19.

[2] Zhao Ye \& Wang Jianguo. Evaluation and Control of Waterfront Urban Landscape--A Case Study of Urban Landscape Planning on the East Bank of the West Lake in Hangzhou, Urban Planning Forum, 2014 (04): 80-87.

[3] Hang Xiaoqiang \& Wu Yaohua. A Discussion on the Spatial Pattern of Large-scale Linear Urban Waterfronts--A Case Study of the Urban Design on both Sides of Xiangjiang River, Lengshuitan District, Yongzhou, Planner, 2015 (05): 55-59.

[4] Liu Hua. An Analysis of the Application of Low Impact Development in the Urban Waterfront Landscape Design, Ecological Economy, 2014 (11): 192-195.

[5] He Zhiyin, Qi Xiaoyu, and Guo Xiaoning. An Analysis of the Waterfront Ecological Culture Corridor Landscape Design, Henan Science and Technology, 2015 (10): 98-100.

[6] Chen Keshi, Lou Qian, and Zhao Yan. An Exploration of the Regeneration Strategy of Harbor City Interface Waterfront--A Case Study of Marseille Old Port in France, Urban Development Studies, 2016 (04): 27-39.

[7] [7] Liang Yuanling \& Zhu Jie. On the Construction of the Planning and Design Strategy of Mountainous City and River Landscape under the Ecological Catalyst Effect--A Case Study of Kuxi River in New Tea Garden District, Chongqing, Construction of Small Towns, 2014 (01): 50-56.

[8] Xian Ning \& Zhao Ruixing. A Primary Exploration of the Waterfront Park Landscape Design in Modern Cities, Design, 2015 (13): 125-126.

[9] Tian Jianzhong \& Peng Xin. A Research on the Waterfront Landscape Design of Urban Ecological Planning--A Case Study of Changfeng County, Engineering and Construction, 2014 (05): 612-614.

[10]Du Xin, Bao Chun, and Zhang He. A Research on the Design Strategy of Waterfront Green Space Landscape in Shenyang, Journal of Shenyang Architectural University (Social Science Edition), 2014 (03): 245-248. 